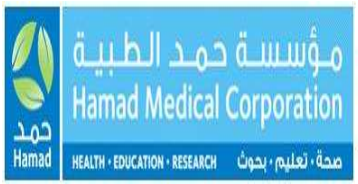

\title{
Reducing the incidence of exposure to blood and body fluids
}

\section{Naglaa Sallam, Dr. Reham Hassan, Dr. Alaedine Shurrab, Dr. Yasser Al Deeb, Dr. Mujahed Shraim}

\begin{tabular}{|c|c|}
\hline & Background \\
\hline & $\begin{array}{l}\text { Blood and body fluids exposure (BBFE) is a } \\
\text { major occupational risk for healthcare } \\
\text { workers (HCW) and is associated with } \\
\text { increased cost } \\
\text { - BBFE exposure (percutaneous or } \\
\text { mucocutaneous) increases the risk of } \\
\text { blood-borne viruses }\end{array}$ \\
\hline a & Nurses are at more risk for BBFE \\
\hline a & $\begin{array}{l}\text { About } 50 \% \text { of BBFE incidents are under } \\
\text { reported }\end{array}$ \\
\hline a & $\begin{array}{l}\text { At Alkhor Hospital (AKH), we have noted a } \\
\text { significant increase in the number of BBF } \\
\text { incidents ( } 6 \text { cases and } 15 \text { cases in } 2017 \text { and } \\
\text { 2018, respectively) }\end{array}$ \\
\hline a & $\begin{array}{l}\text { The Hemodialysis unit at AKH was chosen to } \\
\text { be the starting setting for our Ql project }\end{array}$ \\
\hline & $\begin{array}{l}\text { - Needle-stick injury (NSI) is a common } \\
\text { occurrence in dialysis units }\end{array}$ \\
\hline & $\begin{array}{l}\text { - } 80 \% \text { of dialysis patients would require } \\
\text { needle handling before \& after dialysis }\end{array}$ \\
\hline & $\begin{array}{l}\text { - Blood splash exposure is significantly } \\
\text { higher than other clinical areas }\end{array}$ \\
\hline & Aim and objectives \\
\hline & $\begin{array}{l}\text { To increase median days between incidents } \\
\text { of BBFE in AKH from } 13 \text { days to } 50 \text { days by } \\
\text { the end of March } 2019 \text { and to } 100 \text { days by } \\
\text { the end of December } 2019\end{array}$ \\
\hline a & $\begin{array}{l}\text { Identify any gaps in HCW knowledge, } \\
\text { practice, and attitudes about risk of BBFE }\end{array}$ \\
\hline$\square$ & $\begin{array}{l}\text { Enhance knowledge and safe practice for } \\
\text { BBFE prevention based on any identified } \\
\text { gaps }\end{array}$ \\
\hline a & Improve BBFE reporting culture \\
\hline 口 & Pay consideration to staff satisfaction \\
\hline & Study measures \\
\hline & $\begin{array}{l}\text { Nome Measure } \\
\text { Number of Days between Incidents } \\
\text { cess Measure }\end{array}$ \\
\hline $\begin{array}{l} \\
a \\
a \\
\text { Balt }\end{array}$ & $\begin{array}{l}\text { The BBFE risk awareness score } \\
\text { The attitude \& practice score } \\
\text { Percentage of compliance to BBFE safe } \\
\text { practice } \\
\text { ance Measures }\end{array}$ \\
\hline & $\begin{array}{l}\text { Reporting exposure score } \\
\text { Percentage of staff satisfaction }\end{array}$ \\
\hline & Methods \\
\hline$\square$ & $\begin{array}{l}\text { The dialysis unit's baseline process map and } \\
\text { cause and effect diagram were studied }\end{array}$ \\
\hline$\square$ & $\begin{array}{l}\text { PDSA cycles were established and } \\
\text { implemented for data collection and } \\
\text { intervention tools }\end{array}$ \\
\hline$\square$ & $\begin{array}{l}\text { Pareto chart was used to study the priority } \\
\text { areas with most prevalent cases of BBFE }\end{array}$ \\
\hline & $\begin{array}{l}\text { - This showed that the incident of BBFE in } \\
\text { three units (Emergency, Operating theater } \\
\text { and Dialysis unit ) accounted for 60\% of all } \\
\text { BBFE incidents at AKH (Fig 1) }\end{array}$ \\
\hline$\square$ & $\begin{array}{l}\text { We collected anonymized data about BBFE } \\
\text { incidents, which were submitted infection } \\
\text { control department }\end{array}$ \\
\hline & $\begin{array}{l}\text { - This showed that } 80 \% \text { of all incidents } \\
\text { were related to NSIs and that } 47 \% \text { of all } \\
\text { incidents occurred among staff nurses (Fig } \\
\text { 2) }\end{array}$ \\
\hline
\end{tabular}
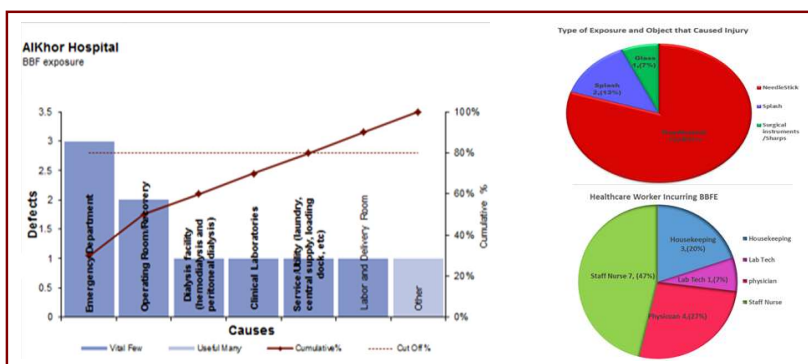

Fig 1: Pareto Analysis

Fig 2: BBFE incidence at AKH
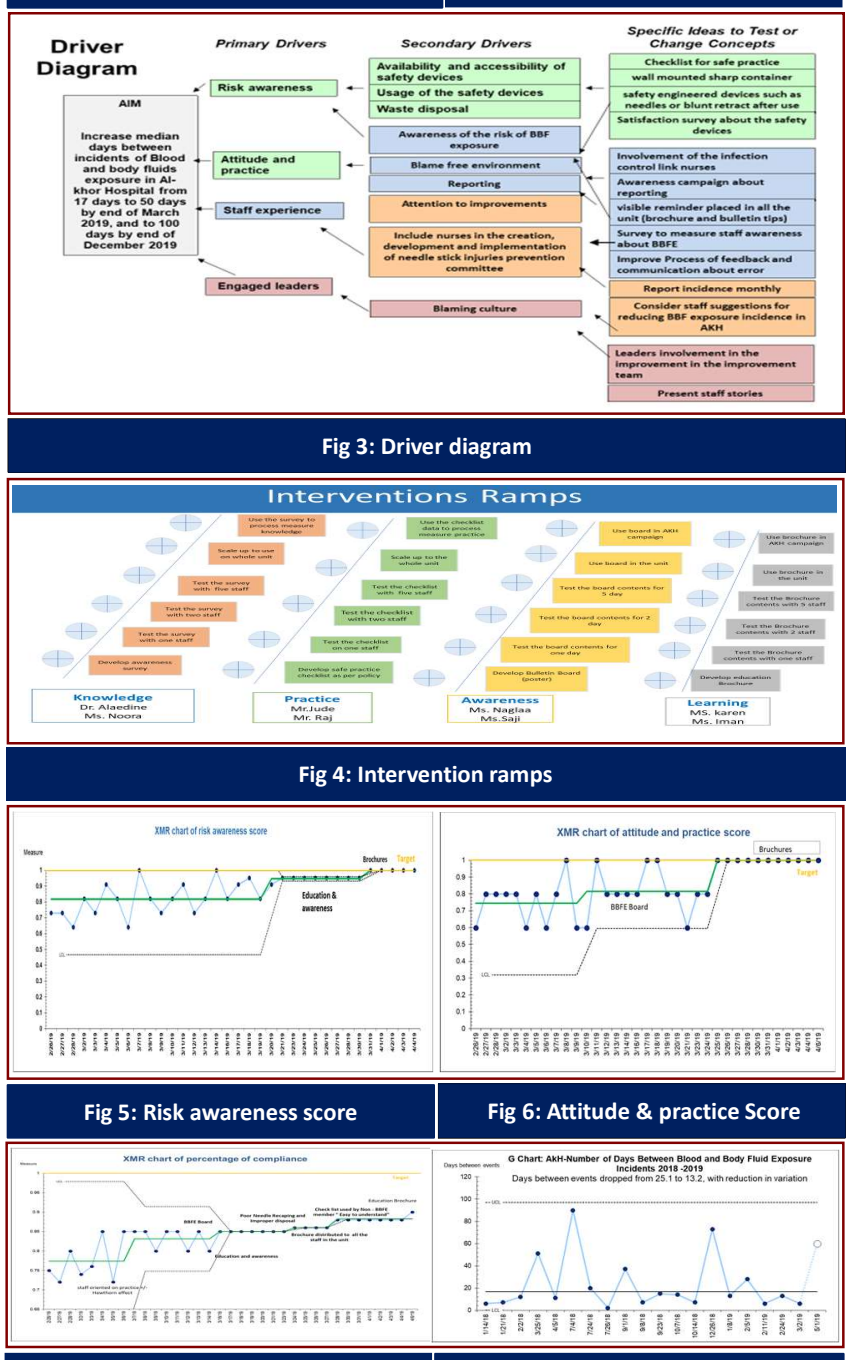

Fig 7: Compliance to BBFE safe practice $\quad$ Fig 8: No. of days between incidents

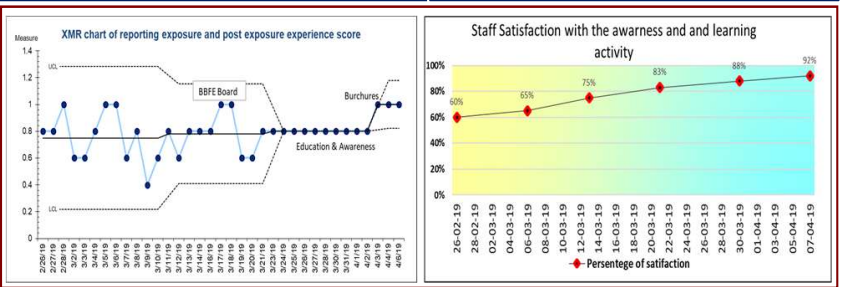

Fig 9: Reporting exposure score

\begin{tabular}{|l|}
\hline \multicolumn{1}{|c|}{ Methods } \\
\hline a driver diagram of primary and secondary \\
drivers for the project (Fig 3) \\
$\square$ On bases of learning and testing, interventions \\
ramps with multiple PDSA cycles were designed \\
around the following four main domains (Fig 4) \\
$\square$ Knowledge \\
- To test the knowledge of HCWs BBFE using a \\
survey \\
Safe practice \\
- Assessing HCWs' compliance with the \\
recommended safe practice \& use a safe \\
practice check list to assess changes in safe \\
practice \\
$\square$ Awareness \\
- Address gabs in HCWs' knowledge \& practice \\
about risk of BBFE using a bulletin board \\
learning : \\
- Circulate brochures to remind HCWs' about \\
the risk of BBFE and safe practice \\
\hline \multicolumn{1}{|c|}{ Results } \\
\hline
\end{tabular}

$\square$ Risk awareness score of BBFE among HCWs increased from $82 \%$ to $100 \%$ (Fig5)

The attitude about reporting BBFE and safe practice score increased from $75 \%$ to $100 \%$ (Fis 6

- Compliance with safe practice improved from $77 \%$ to $86 \%$ (Fig 7 )

Days between BBFE events dropped from 25.1 to 13.2 (Fig 8). However, this can be explained by improvements in the knowledge about risk of BBFE \& reporting awareness by the staff. Therefore, we expect to observe increase in the median number of days between BBFE events in the future

Reporting BBFE increased from $75 \%$ to $100 \%$ (Fig 9)

- Staff satisfaction with the educational tools improved from $65 \%$ to $96 \%$ (Fig 10)

\begin{tabular}{|l|}
\hline \multicolumn{1}{|c|}{ Conclusions } \\
\hline$\square$ There was a gap in HCWs' safe practice \\
regarding BBFE before we start the Ql project \\
$\square$ Awareness board, circulating brochures, and \\
awareness sessions were associated with \\
improvements in HCWCs' knowledge, \\
compliance with safe practice \& attitudes about \\
reporting BBFE \\
$\square$ We observed reduction in the median number \\
of days between BBFE event, which is explained \\
by increase in reporting of BBFE due to our \\
interventions. This initial increase in reporting is \\
expected \& has been seen in previous studies. \\
However, we expect reverse in the future \\
\hline
\end{tabular}

Sustainability plan \& next steps

$\checkmark$ Spot check for knowledge \& practice

Annual awareness sessions for HCWs

Maintain the bulletin board \& circulating the brochures as a reminder

Spread the project to Medical and Surgical wards \& further scale up plan will be drawn

- Plan for work environment changes such as introducing safe practice equipment to reduce BBFE risk and incidence 